\title{
ORGANIZACIÓN COMUNITARIA DE LOS YUMANOS OCCIDENTALES: UNA REVISIÓN ETNOGRÁFICA Y PROSPECTO ARQUEOLÓGICO*
}

\author{
Por \\ Don Laylander**
}

\begin{abstract}
RESUMEN
Existen actualmente múltiples aspectos sobre la cultura de las sociedades aborígenes de Baja California antes del contacto europeo que se desconocen en gran medida. Uno de estos aspectos es la organización de la comunidad ¿Acaso se tenía una organización a nivel de banda o era tribal? ${ }_{\iota}$ Cómo podemos aproximarnos a esta información?

El autor de este trabajo presenta de una forma crítica las experiencias de distintos etnógrafos de este siglo con respecto a este tema y en base al análisis cuidadoso de la información propone una hipótesis. Finalmente, demuestra que el uso de estudios arqueologicos es útil como apoyo en el conocimiento de este aspecto sociocultural de los pueblos indígenas.
\end{abstract}

\section{ABSTRACT}

At present many aspects about the culture of aboriginal societies of Baja California before European contact still unknown. One of these aspects is community organization. Were they organized at a band or tribal level? How can we get a look at this information?

The author of this article presents in a critical way the experiences of different ethnographers of this century with respect to this subject, and after analyzing the information he proposes a hypothesis. Finally, he demonstrates that archaeological studies can help in the understanding of community organization of native societies.

\section{INTRODUCCIÓN}

En este documento se revisa e intenta evaluar la información etnografica relativa a patrones de organización de la comunidad que existieron entre los yumanos occidentales en tiempos anteriores al contacto. En la bibliografía básica sobre este tema se han realizado interpretaciones divergentes que a menudo no reconocen explícitamente tales diferencias y por lo tanto no llegan a evaluarlas. Un elemento clave para pretender valorizar la sobrevivencia y evolución de la cultura prehistórica

- Traducido del inglés por Diana Guerrero González y Julia Bendímez.

** Arqueólogo de Distrito para el Departamento de Transporte de California, San Diego. 
es mediante un entendimiento sólido y crítico de la organización comunitaria. En particular, en el estudio de los restos arqueológicos de la región, tiene considerable importancia el uso de modelos etnográficos apropiados de organización comunitaria.

Iniciaremos este trabajo definiendo las condiciones y el alcance de esta discusion para después presentar una revisión histórica detallada de las investigaciones etnográficas y sus interpretaciones. Posteriormente, se hará un intento por valorar los méritos relativos a los diversos enfoques concernientes a la organización comunal basados en la evidencia con que contamos, y finalmente, se destacarán algunas de las implicaciones de modelos etnográficos confrontados y se hará una valoración preliminar del testimonio de los registros arqueológicos sobre estos temas.

El término "organización comunitaria" será utilizado en este documento para hacer referencias a aspectos culturales que incluyen: la composición social del grupo de personas que ocupaban un asentamiento común, la naturaleza de su liderazgo, el patrón estacional de sus migraciones, su integración con otros grupos y sus dispersiones, así como las posiciones políticas y económicas que asumían para controlar la tierra y sus recursos.

Los yumanos occidentales son aquellos individuos de habla yumana que viven en el norte de Baja California y en el sur de California; al oeste del río Colorado y su delta (ver figura 1). Incluye a los kiliwa, los paipai y a los que hablaban el grupo de dialectos o lenguajes que han sido convencionalmente llamados "dieguefios"1 , lamados también Ipai, Tipai, Kumeyaay, etc. Los hablantes diegueffo-este - pueblos agricultores ubicados en el Valle Imperial y en el río Colorado - serán excluidos, como también los Cucapá, los Quechan, Halchidhoma, Mohave y Maricopa. La organización comunitaria aborigen de los yumanos del delta del río, divergia fuertemente de sus parientes occidentales. Aunque no eran uniformes culturalmente, los yumanos compartían elementos importantes en su adaptación ecológica y social. Estas semejanzas sugieren la utilidad y legitimidad de combinar, o por lo menos comparar la escasa información etnografica disponible sobre la estructura comunitaria aborigen de los grupos yumanos.

1 N. del E. En la zona norte desde la altura de la ciudad de Ensenada hasta Escondido, California, por el lado oeste y hasta el Valle Imperial en California habita uns sociedad yumana que habla varios dialectos de una sola lengua. El término dieguefio aparece con relación a la Misión de San Diego de Alcalá. Algunos autores dividen el diegueño en diegueño del sur, diegueño del norte y diegueño del oeste, y a su vez otros subdividen el diegueño en ipai y tipai. Además de lo anterior, es también necesario aclarar que la lengua kwal y la kamia pertenecen a este grupo lingüistico. La antropología en Baja Califormia ha considerado el término kumiai representativo de estas distintas nomenclaturas. 


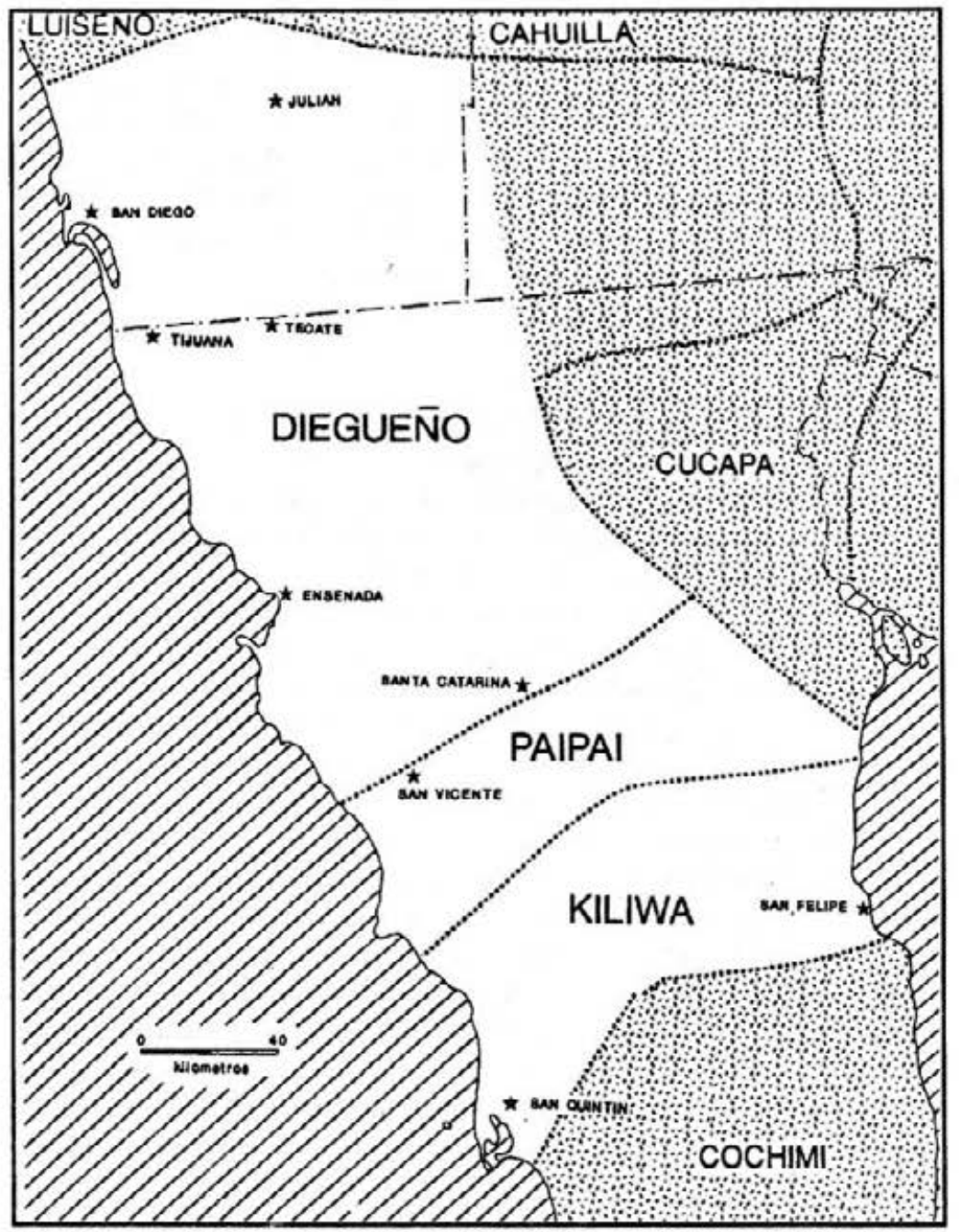

FIGURA 1. La región yumana del sur del condado de San Diego y norte de Baja California.

El período bajo discusión es el "presente etnográfico" etapa hipotética que data de tiempos justo antes de que el impacto de las exploraciones y los movimientos modernos iniciados por los europeos empezaron a alterar los patrones culturales de los pobladores de la región. Los registros 
etnográficos son posteriores a esa etapa; sin embargo, en lo que se enfoca la discusión es en una abstracción que se infiere de las observaciones historiográficas y generalizaciones que se recuerdan sobre la historia, separando los elementos de aculturación más obvios de la tradición auténtica más antigua. Existen buenos argumentos que favorecen la consideración de esta abstracción como una meta interesante y útil; no obstante, su base epistemológica precaria no debe olvidarse.

\section{REVISIÓN ETNOGRÁFICA}

Existen anotaciones etnográficas sobre los yumanos occidentales en los registros de los primeros exploradores y misioneros, así como de los visitantes y residentes de la región durante el siglo XIX. Estas observaciones tienen alguna relevancia para el presente tema, particularmente debido a que identifican la ubicación de asentamientos aborígenes, las estaciones de ocupación y el tamaño de los grupos que las ocupaban. Sin embargo, ninguno de estos registros da por sí solo una imagen detallada y coherente. Típicamente tales relatos reflejan comparaciones superficiales de las instituciones de los yumanos occidentales con modelos europeos o con poblaciones "tribales" que pertenecen a otras regiones o eras.

La disciplina de la antropología alcanzó el área de los yumanos occidentales a principios del siglo XX, con el trabajo de C. G. Dubois, Thomas T. Waterman, Eduard S. Curtin y Edward H. Davis. Estos investigadores registraron y publicaron información etnográfica valiosa de los yumanos occidentales que vivían dentro de los Estados Unidos, particularmente los ipai o diegueños del norte. Reflejando la tendencia de la antropología en ese tiempo, el enfoque principal de los primeros trabajos era en mitología y ceremonia; esos observadores registraron poca información relativa a la organización comunitaria. Esta tendencia cambió a fines de la primera y segunda década del siglo XX. Alfred L. Kroeber, Edward W. Gifford y Leslie Spier escribieron algunos análisis importantes sobre la organización comunitaria de los yumanos occidentales. La ubicación geográfica de estos estudios estaba otra vez al norte de la frontera internacional, pero en esta ocasión se trataba primordialmente de estudios sobre los tipai, kumeyaay y diegueños del sur.

Edward Winslow Gifford -como asistente y colega de Kroeber en la Universidad de California - realizó uno de los primeros registros para salvaguardar información etnográfica en varias partes de California y en regiones adyacentes. De diciembre de 1916 a enero de 1917, pasó cinco semanas trabajando con informantes en el sur de California, incluyendo diegueños y hablantes de idiomas uto-azteca. Entre los informantes de 
Gifford estaban James McCarty Hetmiel del área de Campo; José Largo Hetmiel del área de Campo; José Largo Hetmiel, Angel Quilp, y Hutcukal del Valle Imperial occidental y Tomaso Curo de Mesa Grande. De este trabajo de campo inicial resultó la publicación de Gifford: Clans and Moieties in Southern California (1918), así como algunos comentarios adicionales publicados en Miwok Lineajes and the Political Unit in Aboriginal California (1926). Posteriormente, de diciembre de 1921 a enero de 1922, Gifford y Robert H. Lowie trabajaron con informantes cucapá en el suroeste de Arizona, fue ahí en donde encontraron a su informante, un paipai (Akwa'ala) llamado Liebre (Nalwaxaw). El material etnográfico publicado de este único informante paipai contenía poca información relativa a la organización de la comunidad (Gifford, 1928). Finalmente, Gifford trabajó con informantes kamia (diegueños del Valle Imperial) en diciembre de 1928 y enero de 1929; los resultados de este trabajo los publicó en Los Kamia del Valle Imperial (1931). Para este último estudio, Gifford usó seis informantes: Charles Beans, Narpai, Rosa (esposa de Narpai), José (Hat painya), Charles Hilmiarp y Placidus Aspa. Varios de estos informantes tenían conecciones próximas con los Cucapá o con los Quechan; en cualquier caso, los diegueños del Valle Imperial eran más similares, culturalmente hablando, a los yumanos del delta y del río - pueblos agricultores principalmente-, que a los yumanos occidentales que eran fundamentalmente cazadores y recolectores.

Gifford reconoce, en su primer escrito (1918), la existencia de clanes, simus (chumules) ${ }^{2}$ que eran exógamos ${ }^{3}$ y patrilineales, grupos que probablemente se ubicaban geográficamente tanto entre los diegueños del norte (ipai) como entre los sureños (tipai). La localización era menos clara en el caso de los chumules ipai, hecho que parece ser admitido por Gifford como el resultado de cambios inducidos, más en los ipai que en los tipai, por interferencia externa durante los periodos misionales y posteriores. Ambos grupos tenían jefes de chumul (kwapais) que entre los ipai eran según se reporta oficios hereditarios, mientras que entre los tipai eran seleccionados por los miembros del clan. Una comunidad ipai de chumul multiple en Pamo se decía, había tenido un jefe electo de la villa (llamado también kwapai) además de los kwapais heredados de los chumules.

2 N. del E. Es una organización semejante o análoga al clan, localizado en la zona habitada por las comunidades de habla yumana. Es un término originario de las lenguas yumanas. A través del tiempo distintos investigadores lo identifican y le dan distintas escrituras como son: chumul, shumul, simul, cimul, shimul, etc.

3 N. del E. La exogamia es una regla matrimonial para la prevención del incesto; define que parientes quedan excluidos como cónyuge o pareja sexual (Diccionario de Antropología, 1980). 
Gifford y Lowie (1928) reportan la existencia entre los paipai de grupos patrilineales llamados "sumulla", similares a los chumules ipai y tipai: de hecho, algunos nombres de chumules eran idénticos para todos los grupos. Sin embargo, los chumules paipai, se decía, no estaban localizados en lugares específicos, sino dispersos (Gifford y Lowie, 1928:340). El estudio realizado por Gifford (1931) sobre los kamia del Valle Imperial, también reportó patrilineajes exógamos, algunos con nombres que correspondían con los de los diegueños del extremo occidente. Además, relata que los kamiai se desplazaban de un lugar a otro sin tener una aldea permanente. ${ }^{4}$ El jefe kamia (kwaipai) no era hereditario y sólo había un líder para un grupo kamia a la vez, y no existía un kwaipai para cada chumul.

El etnógrafo Leslie Spier condujo un trabajo de campo en el área yumana occidental; este trabajo, aunque limitado, aportó información de importancia central por el detalle y la observación crítica con que el autor reportó e interpretó sus datos. Spier entrevistó, cerca de Campo, a sólo un informante diegueño del sur, James Mc Carty (quien había sido también uno de los informantes de Gifford) durante 12 días, en los meses de julio a agosto de 1920. Como resultado de este trabajo se publicó Southern Diegueño Customs (1923).

El estudio de Spier describe un clan patrilineal y exógamo o cimul (chumul) como la unidad clave de organización social entre los tipai. Cada chumul estaba "definitivamente asociado a una localidad restringida que era probablemente su casa usual de verano" (Spier, 1923:299) (ver figura 2), aunque la residencia uxorilocal ${ }^{5}$ podía ocurrir ocasionalmente (Spier, 1923:310). La conciencia de nación entre los tipai era superficial; "La unidad real, reforzada por la cohesión social, es el grupo local donde un clan predominaba, quizás con la exclusión de todos los demás (Spier, 1923:298-299). Al informante de Spier se le había dicho de niño (quizás en los años treintas del siglo pasado) que los chumules "primero vivían en localidades claramente segregadas, pero empezaban a mezclarse" (Spier, 1923:301). Un chumul (o quizás varios chumules llamados igual) estaba también frecuentemente asociado con varias localidades diferentes, de acuerdo con los datos de Spier. Cada chumul tenía un kwaipai "el cargo es generalmente herditario, pero con un elemento de selección informal entre los posibles herederos, con exclusión del resto de la gente" (Spier, 1923:309).

4 La existencia de chumules sin localización fija y liderazgo de alto nivel fue también çaracterístico de los agricultores cucapá, quechan, mohave y maricopa.

$\mathrm{N}$. del E. Se dice del matrimonio que vive regularmente en el domicilio de los padres de la esposa o en las proximidades (Diccionario de Antropología, 1980). 


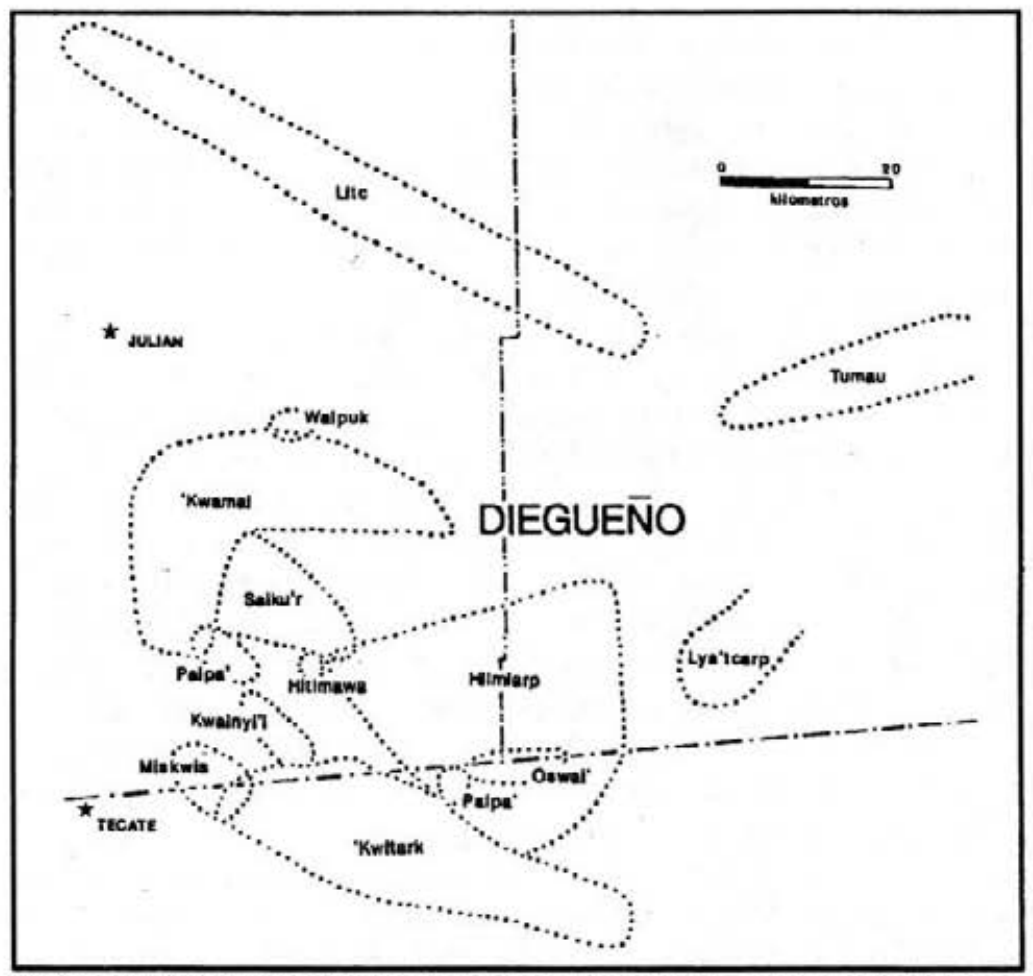

FIGURA 2. Territorios de chumules diegueños en el sureste del condado de San Diego y extremo norte de Baja California, FUENTE: Spier (1923).

El aspecto más interesante del relato de Spier de la organización comunal fue la descripción que hizo de los movimientos estacionales:

La ocupación de los territorios de clan era estacional. Durante el invierno vivían en grupos de afiliación de clan mezclada y se establecían en las bases de elevaciones en la orilla del desierto del Colorado. En la primavera regresaban a las montañas, manteniéndose de alimentos vegetales silvestres, conforme éstos iban madurando. El verano lo pasaban en sus respectivos territorios, donde vivían en pequeños grupos en los valles. El total del territorio no fue ocupado en una sola vez: cuando los recursos de un sitio eran sobreexplotados a nivel cacerfa o ya sea que los frutos maduraran en otros sitios ellos seguían adelante. Sin embargo, en el curso de un año todos sus asentamientos habfan sido ocupados (Spier, 1923:306). 
Los territorios de los chumules ${ }^{6}$ que reporta Spier no consistían sólo en los lugares donde estaba ubicada una aldea, sino en áreas más cxtensas que frecuentemente incluían más de un asentamiento denominado. En teoría, los miembros de un chumul "no podían recolectar frutos ni cazar dentro del territorio de otros sin su permiso. Los dueños ordenarían a los transgresores que salieran y reforzarían su voluntad con armas" (Spier, 1923:306).

El compendio etnográfico de Kroeber, "Handbook of the Indions of California", estuvo casi terminado en 1918 y fue publicado en 1925. Para su trabajo sobre la organización comunitaria diegueña, Kroeber se apoyó fuertemente en el trabajo de Gifford y, en menor grado, en el de Spier, pero presentó un resultado más enfático que las conclusiones de ellos. Kroeber reportó que los diegueños (implícitamente, tanto ipais como tipais) estaban divididos en clanes ${ }^{7}$ (chumules) exógamos y patrilineales, "definitivamente asociado con localidades en la mentalidad nativa" (Kroeber, 1925: 719). Este sistema se consideraba "como un vestigio rudimentario" comparado a otros sistemas más al norte de California, aparentemente porque los nombres totémicos de los chumules y los [moieties] totémicos ${ }^{8}$ no existían entre los diegueños. Kroeber especuló que los chumules diegueños se originaron en grupos residentes exógamos.

Peveril Meigs III, un geógrafo asociado con la Universidad de California, hizo investigación etnográfica de los yumanos de occidente en el norte de Baja California en los años de 1928, 1929 y 1936. En el verano de 1928, Meigs pasó dos semanas en el norte de Baja California, aparentemente la mayor parte del tiempo con los kiliwa de Arroyo de León. Entre los principales informantes kiliwa estaban Vicente Espinoza, José Espinoza y Emiliano Uchurte. En el verano de 1929, Meigs pasó de nuevo una semana con los kiliwa del Arroyo de León y después visitó por una semana más a los paipai y a los diegueños de San Isidoro, Santa Catarina, La Huerta, Nejí y otros sitios más. En 1936 viajó durante siete días en las porciones norteffas del área. Entre los informantes paipai de Meigs estaban María Uchua, Calendario, y José Domingo Castro; entre sus informantes dieguefios estaban Guillermo y Felipe de La Huerta, Calistra Tenjí de Nijí y Juan

6 Es notable que algunos de los asentamientos chumul reportados por Spier estaban ubicados en el desierto, no en territorio montañoso de verano.

7 N. del E. Un clan es un grupo de parentesco unilateral que mantiene la ficción de su descendencia común de un antepadado remoto, generalmente legendario o mitológico (Diccionario de Antropología, 1980).

$8 \mathrm{~N}$ del E. Moieties son grupos de parentesco grandes que dividen a una sociedad por la mitad y Totem es un objeto, animal o planta tenida en especial consideración por parte de un individuo o grupo social. 
Cuffurr de San José de la Zorra. En 1939 Mcigs publicó una monografía sobre los kiliwa que también incluyó información resumida sobre sus vecinos del norte. Los artículos sobre los paipai y los diegueños no aparecieron sino hasta décadas más tarde (Meigs, 1971, 1972 y 1977).

De acuerdo con Meigs, los kiliwa estaban organizados en "linajes o clanes definitivamente asociados, en la mente de la población, con localidades geográficas específicas" (Meigs, 1939:16). El más bajo de dos niveles de grupos de parentesco, el maselkwa, cra "virtualmente sinónimo de ranchería", ocasionalmente varios maselkwas estaban agrupados como un linaje mayor, el ichiupu. Juntos maselkwas e ichiupus corresponden a unidades llamadas chumules y términos similares entre los diegueños y paipai. Los chumules diegueño y paipai registrados por Meigs estaban fuertemente asociados a territorios específicos (ver figura 3 ). Los miembros de un chumul kiliwa, según se reporto, habían hecho caminatas estacionales fucra de sus propios territorios, incluyendo visitas a huertos de piñon en el otoño y a San Felipe en la costa del golfo en la primavera.

A fines de la década de 1930, Philip Drucker, otro antropólogo de la Universidad de California, llevó a cabo una parte de lo que era quizás el más depurado proyecto de rescate etnográfico: Culture Element Distributions: Southern California (1937). Este trabajo recolectó información etnográfica en relaciones estandarizadas por región, de 2,000 a 3,000 items, con características o elementos culturales marcados como presentes o ausentes de acuerdo a un informante dado, algunas veces son detalles adicionales en forma de narración agregados al reporte. Drucker fue responsable de las listas que cubrían la mayor parte del sur de California, oeste de Arizona y norte de Baja California (Drucker, 1937 y 1941). El primer período de trabajo de Drucker fue en 1934-1935, que incluyó "algo más de tres meses de trabajo de campo" (Drucker, 1937:1). De este trabajo produjo 19 listas de elementos culturales, 6 de ellas de informantes diegueños. Las listas diegueñas provinieron de dos informantes "diegueños del oeste" (i.e. ipai), María Alto y Francisco Beltrano ambos de la reservación San Pascual y por lo menos el primero, integrante del chumul Matewirr, dos informantes diegueños del norte (también ipai), Petra Corta del chumul Letcap y Tomás Curo del chumul KuKuR, y de dos informantes "diegueffos del desierto" (e.g. kamia), Lino Letcap de Vallecitos y el chumul Letcap, y Santos López, de parentesco mezclado, cuya madre pertenecía al Kwatl Kumiai, con una base de invierno al este de Campo. El segundo período de trabajo de campo de Drucker tuvo lugar en la primavera de 1938, del que obtuvo once listas más de elementos. Estas últimas, en algunos casos, fueron producto de las respuestas de varios informantes pertenecientes a un grupo etnográfico dado, en ellos se hacían 


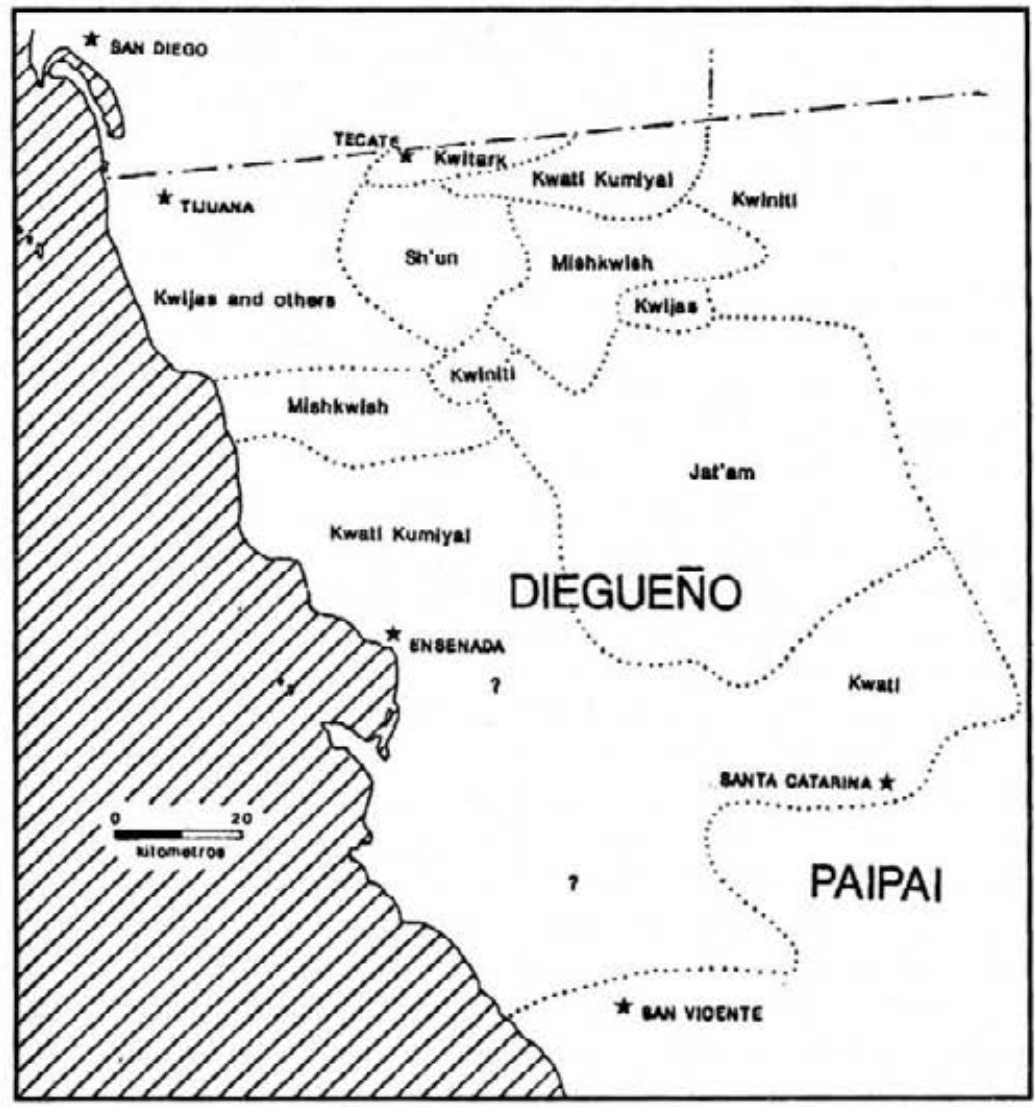

FIGURA 3. Territorios chumules diegueños en el norte de Baja California. FUENTE: Meigs (1939).

notar los desacuerdos entre los informantes. Una lista de información sobre los diegueños se obtuvo de tres informantes en La Huerta: Juan Largo, Juan Aldama y Bernardo Salgado, otra lista paipai ("Akwa'ala") se obtuvo de Petrocina Cuñedo, cuya madre pertenecía al chumul Kwatl de habla diegueña.

La información de Drucker sobre organización comunitaria tendía a apoyar la antes recopilada por Gifford y Spier. Generalmente, los informantes confirmaban la presencia aborigen de grupos de parentesco exógamo, patrilineal y una fuerte tendencia hacia una residencia virilocal ${ }^{9}$ después

9 N. del B. Virilocal es aquel matrimonio que vive en el domicilio de los padres del esposo (Diccionario de Antropologla, 1980). 
del matrimonio. La ubicación de los chumules no se percibe claramente en los grupos del lado de Estados Unidos; pero sí se manifiesta para los diegueños de La Huerta y los paipai. La propiedad privada, la propiedad comunal así como los derechos de recolección generalmente eran negados. No obstante, para los diegueños de Estados Unidos los derechos para recolección en zonas con fronteras definidas era afirmado por lo general. Las referencias a tipos de vivienda de inviemo en Baja California sugieren cambios estacionales de vivienda. Los diegueños de Estados Unidos acordaron que reconocían a un jefe de chumul hereditario, llamado Kwaipai. Se pensaba que la posición era generalmente heredada por primogenitura. El que los kwaipais hayan ocupado el cargo por acuerdo de la tribu, partido o distrito era explícito y unánimemente negado. Los informantes de Baja California acusaron la presencia de jefes de aldeas sólo como innovaciones recientes, sin precedentes en épocas anteriores.

Katherine Luomala y Gertrude Toffelmier trabajaron con informantes diegueños en 1934 y de nuevo en 1962. El enfoque primario fue la búsqueda de información acerca de chamanismo, pero también recopilaron información relevante sobre la organización de la comunidad (Toffelmier y Luomala, 1976 y 1978). Según referencias dispersas, parece que el trabajo de 1934 fue hecho en el verano y principios de otoño de ese año, básica o exclusivamente con un solo informante, un chaman ipai de aproximadamente cincuenta años, cuyo padre no era indígena y su madre era miembro del chumul Neeix (Toffelmier y Luomala, 1936:135; Luomala, 1976:251, 265-270; ver también Heizer, 1978:750). En 1962 se realizaron dos meses adicionales de trabajo de campo con informantes ipai y tipai en Campo (Heizer, 1978:750). La discusión de Luomala "Flexibilidad en la afiliación del clan entre los diegueños" (1963) parece haberse basado en el primer episodio de trabajo de campo (Luomala, 1976:245) así como en la bibliografía etnográfica y etnohistórica publicada. Para su síntesis de etnografía diegueña (1978) usó fuentes publicadas y probablemente también observaciones de campo no publicadas.

Luomala, en su interpretación de la organización comunitaria diegueña, enfatizó comentarios de observadores anteriores en cuanto a la posible naturaleza "rudimentaria" del sistema chumul, su posible evolución de un sistema de banda local sin parentesco, y las inseguridades de la ubicación chumul. Luomala sugirió que el sistema diegueño combinó "bandas poco o levemente organizadas" con un "sistema rudimentario de clan" (Luomala, 1976:258).

En lugar de aceptar el argumento de que las imperfecciones de localizaciones de chumul reflejan impactos postcontacto, Luomala propuso que existían "clanes rudimentarios... entre los diegueños antes de la aculturación pero que asumieron mayor significación con el inicio del contacto 
europeo" (Luomala, 1976:251-252). Se dio énfasis en hacer notar la flexibilidad en la composición de grupos locales de un lugar a otro y a través del tiempo: "los grupos residentes varfan en tamafio, forma y composición de parentesco de lugar a lugar, estación a estación, año con año, de acuerdo a la provisión de alimentos" (Luomala, 1976:257). Sin embargo, las tierras de cacería y recolección eran propiedad de chumules (Luomala, 1976:250). Uno de los principales tópicos de Luomala eran los Kwitxals, "vagabundos" diegueffos quienes acostumbraban llegar a una comunidad extraña argumentando afiliación a un homónimo distante del chumul local. Sin embargo, el nombre "kwitxal" también se aplicaba a un grupo familiar temporáneo o permanente, en proceso de separación de su chumul, quizás en vías de convertirse en un nuevo chumul con un nombre nuevo.

Roger Owen, un estudiante en la Universidad de California en Los Angeles, empezó su trabajo de campo en el norte de Baja California en 1955, cuando pasó en ese lugar dos semanas trabajando con Thomas B. Hinton (Hinton, 1957). Después pasó varias semanas más, durante el verano de 1956, junto con Owen y Judith Joel quienes colectaron información en Santa Catarina. Posteriormente Owen, Joel y Frederic N. Hicks realizaron un proyecto más ambicioso - por su duración-que consistía en establecer su campamento en Santa Catarina, de octubre de 1958 a septiembre de 1959. Las publicaciones de Owen sobre su trabajo etnográfico entre los yumanos occidentales incluyen dos documentos relativos a la organización de estas comunidades (Owen, 1965 y 1966). Sin embargo, la identidad de los informantes de Owen y la naturaleza e intensidad de su trabajo etnográfico no se transmiten claramente en sus publicaciones.

La discusión de Owen sobre la organización de la comunidad yumana del oeste se cita en términos de "bandas" en lugar de grupos explícitamente definidos por descendencia. Sin embargo, aparentemente las bandas de Owen son los mismos chumules que otros etnógrafos describieron. Las bandas se dice, eran grupos con una nomeclatura definida y eran "básicamente virilocales" (Owen, 1965:677). Según Owen, los asentamientos, por lo menos durante períodos históricos, pueden haber incluido varias bandas, en ocasiones antagónicas entre sí. Además, los individuos que residían en los asentamientos fuera de las líneas de parentesco no compartían los recursos de la banda. De acuerdo con Owen, las bandas aborígenes no tenían jefes (Owen, 1966:5), ni organización política o sentido de unidad nacional fuera de la banda. Las bandas que eran semisedentarias pasaban una gran parte del año en su campamento base, pero era esencial, para la supervivencia de la misma, que ésta o parte de ella realizara movimientos estacionales dentro del área que les pertenecía. 
Owen hizo referencia a la naturaleza híbrida de la cultura yumana del occidente, misma que reflejaba variaciones de los recursos disponibles en bases de banda individuales y el casamiento entre bandas, dentro y cruzando líneas linguísticas (Owen, 1965). También enfatizó la "fluidez" de las fronteras (Owen, 1966:5), o en otros términos la ausencia de fronteras sociogeográficas rígidas, lo que permitía que ocurriera un intercambio de ideas y de individuos y que necesariamente algunos grupos salieran de sus campamentos base.

Frederic N. Hicks trabajó con Owen en Santa Catarina en 1958-1959. El alcance del trabajo de campo de Hicks y la identidad de sus informantes no son completamente conocidos. Hicks combinó sus propias observaciones etnográficas con fuentes etnográficas previas y estudios etnohistóricos para presentar una síntesis general sobre la cultura de la gente del "área yumana occidental", que incluía no sólo los grupos denominados aquí yumanos del oeste, sino también la mayoría de los yumanos del delta y del río y los sureffos hablantes del Takic (Uto-Azteca) (Hicks, 1963). También publicó un recuento de aspectos de las culturas yumanas del delta del río que incluyó interpretaciones relativas a los yumanos del oeste (Hicks, 1974).

De acuerdo a Hicks, la unidad sociopolítica de los diegueños, paipai y kiliwa era el linaje denominado políticamente independiente (chumul), en un lugar definido o semilocalizado, exógamo, patrilineal (Hicks 1963:258259). Hicks menciona las posibilidades de variación en la composición del chumul asociada con el flujo demográfico o conflictos personales. Se decía que cada chumul tenfa un líder hereditario (kwaipai). Entre los paipai, y probablemente también entre los otros grupos, cada chumul tenía un área de residencia, donde sus miembros pasaban gran parte del año, pero desde el cual era necesario que realizaran movimientos estacionales para colectar recursos no disponibles en su área base (Hicks 1963:200-201). El uso del área de residencia de un chumul por extranjeros era posible siempre que se obtuviera un permiso. Las áreas identificadas de residencia de los chumules paipai estaban en el interior de regiones intermontanosas o en regiones al pie de los montes en el desierto.

Ralph Michelsen, antropologo de la Universidad de California en Irvine, ha hecho desde 1954 fotografía etnográfica y otro trabajo de campo con los dieguefios, pai pai y kiliwa de Baja California. El alcance de su trabajo y la calidad de sus informantes no son tratados en sus publicaciones. Michelsen ha escrito principalmente sobre cultura material, perotambién escribio un documento importante sobre organizacion comunitaria (Michelsen, 1977). Dice este autor que, los chumules eran patrilineales, grupos con "territorios específicos, bien definidos donde [ellos]... tenían derechos de residencia exclusivos en ciertos ojos de agua" 
(Michelsen, 1977:2) (ver figura 4). Los recursos de temporada eran explotados por la población que se movilizaba constantemente dentro de su aldea de propiedad exclusiva. Algunos chumules tenían subdivisiones, cada uno con su base exclusiva; en ocasiones los chumules compartían su territorio con aliados. "Los kiliwas aseguran que, tradicionalmente, las bandas tenían territorios exclusivos al grado que se tomaban acciones hostiles contra los que traspasaban sus fronteras. En esos casos, se identificaban como transgresores a aquéllos que no tenían relación consanguínea o por afinidad" (Michelsen, 1977:5).

Florence C. Shipek de la Universidad de Wisconsin-Parkside presentó una interpretación divergente de la organización comunitaria dieguefia (1982 y 1988). Shipek ha hecho trabajo de campo etnográfico e investigación de archivo sobre los Diegueños desde 1954; mucho de este trabajo como apoyo a asuntos legales de grupos Diegueños (Shipek, 1988:xii-xvii). Entrevistas etnográficas repetidas fueron realizadas a por lo menos 35 ancianos diegueños de todo el territorio Kumiai, desde Mataguay, Mesa Grande, San Pascual en el norte a Neji, Ha'aa y San José El Zorro (sic) al sur, y de bandas costeras de San Diego a bandas de la montaña y del río Nuevo en el este" (Shipek, 1982:296). Rosalie Pinto Robertson, en particular, fue un informante clave (Shipek, 1984). Las fuentes de campo de Shipek, aparentemente, no incluyeron las comunidades diegueñas sureñas de La Huerta y Santa Catarina, Baja California. Según Shipek, las unidades políticas efectivas de los Diegueños no eran chumules sino bandas territoriales.

Esta organización territorial estaba seccionada por una estructura de parentesco compuesta por entre 50 y 75 clanes denominados, distribuidos en todas las bandas territoriales.... cada clan o chumul tenía segmentos de linaje distribuidos en muchas bandas a través de varias zonas ecológicas dentro de territorio Kumeyaay (Shipek, 1982:297).

La extensión del territorio de cada banda variaba de entre 15 a $50 \mathrm{~km}$ aproximadamente, a lo largo de un sistema hidrológico, con una villa central y algunos asentamientos periféricos: "bajo ciudadoso interrogatorio, los ancianos reiteraban que el Kwaaypaay era normalmente el único adulto varón de su clan en la banda" (Shipek, 1982:297). Cuando moría el Kwaipai de la banda, todos los Kwaipais del territorio diegueño seleccionaban al sucesor, quien también debía ser aprobado por los miembros de la banda. Otras expresiones de unidad diegueña por encima del nivel de la banda incluía a líderes multibanda o líderes nacionales de período histórico y la propiedad colectiva de ciertas tierras "tribales" de recurso y monumentos religiosos. Las tierras que eran propiedad de la nación incluían las áreas de 


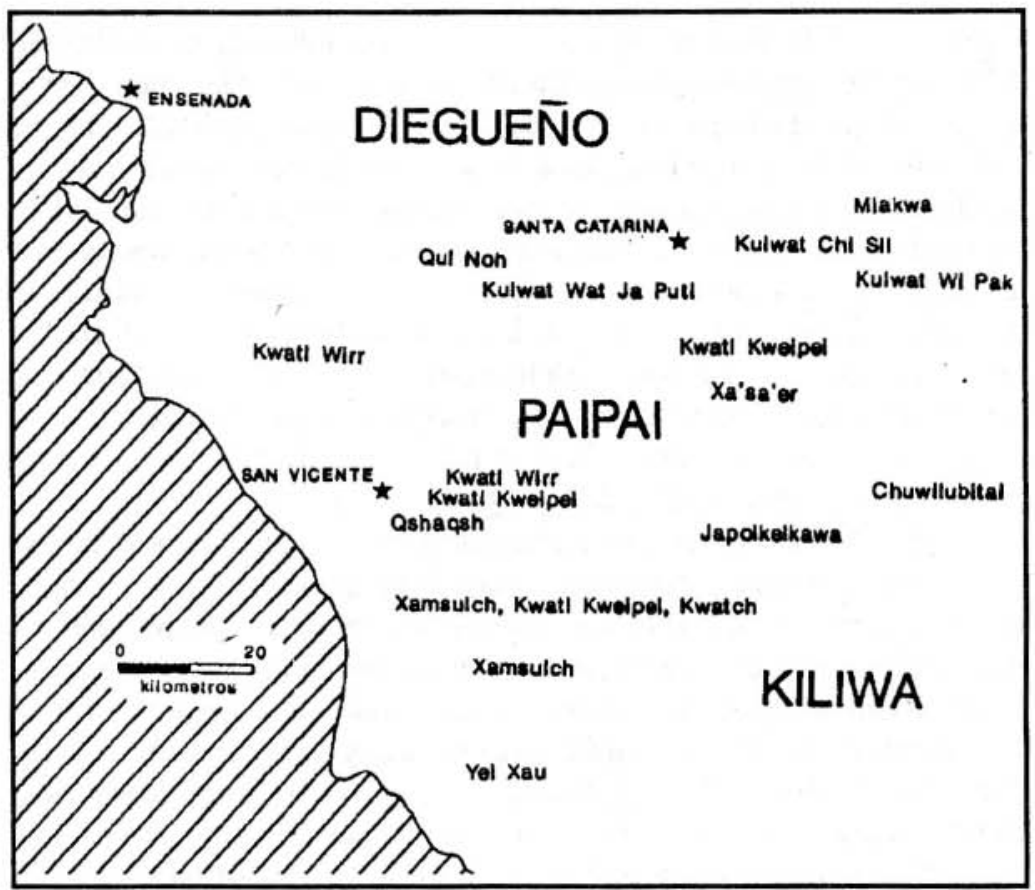

FIGURA 4. Localidades chumul paipai y kiliwa en el norte de Baja California. FUENTE: Michelsen (1977).

recolección del piñón en la sierra de Juárez, de las que se decía estaban abiertas a todos los diegueños pero cerradas para los no diegueños (Shipek, 1982:300-301). Shipek sugiere que el territorio diegueño nacional estaba: 'Limitado por su 'biblia', o historias de creación y profecías. Esta era su tierra santa tanto como Jerusalén es la tierra santa de los hebreos, cristianos y musulmanes" (Shipek, 1988:12). Kuuchamaa (Pico de Tecate), al sur del Condado de San Diego, y Wee'ishpa (Centinela), al norte de Baja California, son mencionados como áreas nacionales sagradas. Sin embargo, la mayor parte del suelo era poseído principalmente por la banda y en segundo plano por los linajes (secciones de chumul) dentro de la banda. Los cambios en la afiliación de la banda de una familia tenían que ser aprobados tanto por la nueva banda a la que se unía y por lo miembros del chumul de la familia dentro de esa banda (Shipek, 1982:301-302).

Uno de los estudios más recientes sobre la organización de la comunidad yumana del oeste fue realizado por Jesús Ángel Ochoa Zazueta quien 
a partir de 1972 hizo trabajo de campo entre los grupos aborígenes sobrevivientes del norte de Baja California. El alcance y las condiciones de ese trabajo de campo no son claros en sus escritos publicados. En su trabajo hizo énfasis en la lingüística, así como en las condiciones contemporáneas de estos grupos, pero también fueron publicadas algunas discusiones relevantes sobre organización comunitaria de los grupos yumanos de occidente en general (Ochoa, 1979 y 1982) y sobre los kiliwa en particular (Ochoa, 1977 y 1978). Desafortunadamente, el uso de las categorías sociales que aplicó Ochoa fue algunas veces confuso, sus comentarios no fueron ubicados en un contexto histórico claro, y por lo tanto existe duda en cuanto a la veracidad de por lo menos algo de su información (cf. Mixco 1983:282-284).

Según Ochoa Zazueta, se distinguen seis en vez de tres distintos grupos étnico-lingüísticos como residuos de las gentes yumanas aborígenes de esta región. Son insuficientes los detalles de los grupos adicionales propuestos como para establecer la validez de los mismos, aunque se conoce alguna evidencia lingüística que tiende a apoyar la posibilidad de subgrupos lingüísticos significativos en la categoría diegueño en Baja California (Ochoa, 1982; Laylander, 1985 y 1987). Sobre los kiliwa, Ochoa aseguró encontrar cuatro niveles de grupos de parentesco exógamo, territorialmente establecidos, que incluían clanes (moieties) (cuatro o posiblemente tres, para los kiliwas como grupo), subclanes (en número de doce) y grupos familiares. Los grupos en los tres primeros niveles se decía eran específicamente estatuidos por el mito kiliwa de la creación, y los clanes y subclanes se reportó eran totémicos. La residencia era "neolocal"10 respecto al asentamiento de grupo de la familia, pero tal movilidad estaba restringida al bien definido territorio del subclan. Según Ochoa Zazueta, había un solo líder con autoridad para el grupo kiliwa como un todo, y su posición era heredada dentro de un clan o subclan específico, estos grupos productores de líderes designados en el mito de la creación.

Una fuente menor de información sobre organización comunitaria diegueffa es la de Lora Cline (1979 y 1984) en su recuento del testimonio etnográfico de Tom Lucas. El padre de Lucas era Cahuilla; sin embargo, él nació en 1903 y está clasificado como el último miembro de la "Subtribu" Kwaaymii del Monte Laguna y Mason Valley (ver Carrico, 1983).

Aun reconociendo que Lucas "sabía poco del sistema de clan", Cline (1979:1) colectó algunas notas relevantes sobre organización comunitaria.

${ }^{10} \mathrm{~N}$. del E. Ubicación de la pareja después del matrimonio sin referencia a la ubicación de cualesquiera de los padres. 
Se aseguró de que los kwaaymii vivían durante el verano en agrupaciones compactas, denominadas "permanentes" en Mount Laguna, pero se cambiaban a campos "temporales" de invierno en Mason Valley, al este en el desierto. "Algunas veces unos kwaaymii iban a la costa a convivir cerca de amigos o parientes" (Cline, 1980:16). El casamiento estaba prohibido entre parientes "más próximos que primos terceros", pero también se decía que la gente "usualmente se casaba en su aldea, su subtribu o su tribu" (Cline, 1980:77), lo que sugería que las aldeas y subtribus reunían grupos de varias descendencias. El jefe de villa o kwaipai, era casi siempre sucedido por su hijo, o, en ausencia de un hijo por su hermano más joven (Cline, 1980:77).

Se han elaborado varios documentos interesantes que exponen e interpretan de una forma resumida aspectos de la etnografía de los yumanos de occidente principalmente en relación con investigaciones arqueológicas en los Estados Unidos (e.g. May, 1975; Graham, 1981; Almstedt, 1982). Estas versiones se han basado en el uso selectivo de las fuentes básicas antes discutidas, junto con un uso menor de documentos etnohistóricos antiguos y el uso de modelos teóricos en algunos casos. Sin embargo, no es necesario revisar aquí esas interpretaciones.

\section{SÍNTESIS ETNOGRÁFICA}

Como se ha visto, las versiones etnográficas disponibles de la organización comunitaria yumana occidental varían considerablemente en el modo en que interpretan esa organización (cuadro 1). Para esta diversidad son posibles varios enfoques.

El primero de ellos sería el de aceptar cada versión como más o menos válida para su propia región, con inconsistencias que reflejan una gran diversidad interna en la cultura yumana occidental. Debe haber un elemento de verdad en esta sugerencia, ya que los patrones culturales yumanos occidentales parecen demostrar variabilidad, tanto entre grupos lingüísticos diferentes como dentro de un solo grupo. Sin embargo, es poco probable que esta diversidad sea la causa de la mayoría de las diferencias en los testimonios.

Un segundo enfoque sería el de generar nueva evidencia con la que se aclararan las divergencias (esto se considerará en la sección final de este documento, en donde se tratarán algunas implicaciones arqueológicas de modelos distintos de organización comunitaria). La adquisición de nueva evidencia etnográfica, es poco factible ya que después de más de dos siglos de intervención externa en el área yumana occidental, la información adicional válidamente asociada con la organización comunitaria 
CUADRO 1. Sumario de enfoques etnográficos en varios aspectos de la organización comunitaria yumana del oeste.

Gifford Spier Meigs Luomala Drucker Hicks Owen* Shipek Michelsen OchoaZ.

Chumul denominado

Chumul patrilineal

Chumul exógamo

Chumul localizado

Chumul en localidades

múltiples

Chumul en localidades

compartidas

Propiedad tierra/recurso

de una familia

Propiedad tierra/recurso

por chumul

Propiedad tierra/recurso por

grupo chumul múltiple

Chumul por Kwaipai

Asentamientos por Kwaipai

$\mathrm{K}$ waipai electo

Kwaipai heredado

Asentamiento estacional

fuera del territorio

$\begin{array}{lll}+ & + & + \\ + & + & + \\ + & + & + \\ \text { S } & + & + \\ \text { S } & + & +\end{array}$

S

$+$

$+\quad+$

$+\quad+$

$+$

+
+
+

$+$

$+$

$+$

$+$

+
+
+
+

NOTA: * La "banda" de Owen igual a chumul. $+=$ Característica afirmada.

- = Característica negada.

$\mathrm{S}=$ Característica presente para algunos grupos.

= Característica no discutida, o discusión ambigua. 
precontacto es escasa. El rescate de información etnográfica temprana, todavía no publicada, como los escritos de J.P. Harrington, puede ser fructífero, así como una búsqueda intensiva de documentos etnohistóricos.

Una tercera aproximación es considerar críticamente las diversas interpretaciones etnográficas de la organización comunitaria yumana $\propto c c i-$ dental que hayan sido ofrecidas para tratar, de esta manera, de detectar las distorsiones causadas por la transformación del periodo histórico, y seleccionar el modelo más apropiado basado en la evidencia existente. En esta sección pretendemos desarrollar la tercera postura.

Organización "nacional". La existencia de unidades de propiedad de nivel supracomunidad, específicamente para entidades étnicas y lingüísticas por lo general, no ha sido reportada o ha sido específicamente negada por los etnógrafos de los yumanos occidentales. Se encuentran notables excepciones en los reportes de Shipek sobre los Diegueños y de Ochoa Zazueta sobre los Kiliwa.

No es fácil rechazar las propuestas de Shipek acerca de la existencia de territorios diegueños nacionales exclusivos y de un proceso de elección a nivel nacional para los kwaipais, dado lo explícito del testimonio que se dice lo apoya. (Desgraciadamente, Shipek no ha sido explícita en cuanto a la identidad de sus informantes, ni sobre las circunstancias en que realizó sus entrevistas, o bien, el grado en que había testimonio contrario, o cómo se evaluaron esos puntos de vista en conflicto). Además, sus propuestas están directamente en contradicción con otros reportes etnográficos, muchos de ellos realizados en periodos más cercanos - en términos de antigüedad - a las condiciones aborígenes que se están discutiendo. Que los informantes hayan ignorado o quisieron ocultar la existencia de tales instituciones nacionales parece inverosímil. En el caso específico del uso de recursos dentro de fronteras lingüísticas diegueñas por no-diegueños, hay evidencia suficiente de una ausencia de exclusividad nacional durante el periodo histórico temprano que se supone refleja prácticas prehistóricas (e.g. MacDougal, 1907; Kelly, 1977). Una posible explicación para la divergencia entre la información entre Shipek y otros reportes es el hecho de que mucho del trabajo de campo de Shipek fue hecho en conección con casos legales de Nativo-Americanos en Estados Unidos, incluyendo los casos de reclamaciones indígenas de tierra de en los años cincuentas y sesentas. Un punto de discusión en esos casos fue si acaso todas las tierras dentro de las fronteras étnico-lingúísticas eran usadas y "propiedad" de los grupos indígenas californianos aborígenes. Los testigos expertos antropólogos para los demandantes nativo-americanos argumentaron que toda la tierra era usada y propiedad de ellos, y que tierras que no eran específicamente 
propiedad por grupos individuales de parentesco o comunidades, eran propiedad exclusiva del grupo étnico-lingüístico (Cf. Heizer y Kroeber, 1976; Stewart, 1978). Esta disputa legal creó un contexto en el que fuertes incentivos estaban presentes para interpretar como aborígenes cualesquier tendencia hacia la unidad nacional indígena que pueda haber surgido como resultado de las confrontaciones del período histórico diegueño con autoridades externas españolas, mexicanas o americanas.

El reporte que hace Ochoa Zazueta sobre el establecimiento de un jefe kiliwa nacional se evalúa con más dificultad debido a la falta de información etnográfica independiente. El testimonio de Meigs, aunque relacionado al período histórico, tiende a apoyar a Ochoa en este punto. Además, las analogías con las instituciones de otros grupos yumanos occidentales deben ser usadas cuidadosamente, porque la cultura kiliwa parece haber sido notablemente divergente de las de los otros yumanos occidentales en varios aspectos (por ejemplo: lingüísticamente, y en el que carecen del característico mito de la creación yumano-takic). Sin embargo, la concentración histórica de los kiliwa sobrevivientes en la zona de Arroyo de León y su necesidad de un vocero para tratar con la sociedad mexicana dominante puede ser también la razón por la cual emerge una unidad nacional entre los kiliwa durante tiempos históricos; hecho que se consideró posteriormente como un aspecto cultural de tiempos del precontacto. Los reportes sobre la existencia de territorios y comunidades basados en el parentesco durante el período aborigen, y la ausencia de algún recuento específico sobre el funcionamiento de liderazgo o unión al nivel de nación favorecen la consideración a nivel tentativo de la segunda opción: que las instituciones kiliwa eran análogas en este caso con aquéllas de los yumanos occidentales careciendo de una unidad nacional aborigen.

\section{Localización del chumul}

El detalle con el cual algunos etnógrafos reportaron asociaciones geográficas de chumules, específicos y denominados, es una evidencia de su ubicación en determinados sitios muy contrariamente al punto de vista de Shipek. Parece más posible que la ubicación en lugares específicos disminuyó y se volvió confuso debido a desplazamientos y a la decadencia demográfica de tiempos históricos, más que al hecho de que se haya creado un nuevo sistema de ubicación de chumules como dice Luomola. Al mismo tiempo hay mucha evidencia, por lo menos sobre el período histórico, en el sentido de que comunidades residenciales en muchas ocasiones no estaban conformadas por un solo chumul y también que grupos de un 
chumul del mismo nombre idéntico estaban asociados con varios sitios diferentes (no sucesivas estacionalmente).

Una interpretación comprometida puede apoyar la mayoría del testimonio etnográfico en esos puntos. En este aspecto, los grupos efectivos del control de tierra de los yumanos occidentales eran chumules, o quizás más apropiadamente segmentos de chumul.

Éstos estaban compuestos de individuos patrilinealmente relacionados (por lo menos en teoría) quienes residían juntos en el territorio chumul por lo menos una porción del año. Mientras que el territorio era exclusivo en principio, puede haber estado normalmente abierto en base a la hospitalidad a afines y a otros grupos que no pertenecían al chumul, asegurándose de que tal apertura no resultara en una excesiva explotación de los recursos que les servían de sustento (agua y piñón, por ejemplo). Los miembros de un chumul que poseían territorio montañoso, pueden haber compartido ese territorio con miembros de otros chumules en verano, y en otras estaciones; a su vez, los miembros del chumul de verano pueden haberse dispersado para disfrutar la hospitalidad de varios de sus parientes en otras localidades. Bajo este aspecto, el chumul era el grupo básico yumano occidental, pero no era una comunidad residencial todo el año, ni tampoco correspondían precisamente a chumules las comunidades residenciales estacionales.

Las dispersas asociaciones de chumules denominados pueden explicarse como el resultado de un proceso de desprendimiento de segmentos de los chumules, en respuesta a los flujos demográficos inevitables en grupos tan pequeños como esos lineajes y en respuesta también, sin duda, a un conflicto aborigen. Secciones de chumules sobresaturados pueden haberse mudado a áreas desocupadas y apropiado de ellas. $\mathrm{O}$ bien, los yernos pueden haber heredado derechos de sus suegros, si éstos no tenían herederos. Algunos chumules pueden haber sido desposeídos de sus propiedades en período de hostilidades. La interpretación sugiere, además, que los kwaipais eran líderes de chumul, en vez de líderes de banda o de comunidad. Es posible que el kwaipai del chumul anfitrión haya ejercido alguna autoridad con los grupos invitados en una comunidad residencial temporal; como es posible también que un chumul de nombre único puede haber tenido tantos kwaipais diferentes como tenían segmentos localizados separadamente, no habiendo evidencia de kwaipais de chumul de asentamientos múltiples.

\section{Estabilidad del asentamiento}

Los registros etnográficos asocian a los chumules con territorios, en lugar de aldeas con una nomeclatura específica. Se han reportado localidades diversas cada una con su nombre propio, agrupado dentro de áreas 
relativamente circunscritas. Estos puntos, junto con el testimonio explícito de Spier, sugiere que los asentamientos no eran villas permanentes sino que se cambiaban libremente dentro del campo de recursos propiedad del chumul, de acuerdo a la disponibilidad del recurso, o del estado de las relaciones sociales intragrupo, entre otros factores.

\section{IMPLICACIONES ARQUEOLÓGICAS}

La contribución de la información etnográfica sobre la organización comunitaria yumana occidental ha sido relativamente rica; sin embargo, actualmente, en cuanto a potencial adicional está más bien limitada. La contribución de información arqueológica ha sido hasta ahora leve, pero la arqueología puede tener un potencial creciente para contribuciones futuras. Modelos derivados etnográficamente pueden ser utilizados legítimamente como hipótesis de trabajo para interpretar datos arqueológicos pero esos datos deben ser usados para probar y refinar los modelos etnográficos.

La argueología, en la actualidad, no puede contestar con efectividad todas las preguntas sobre organización comunitaria que la etnografía descubre. Sin embargo, han sido identificadas varias estrategias arqueológicas para probar porciones de los modelos de organización comunitaria yumana occidental. Estas estrategias incluyen clasificación de sitios, análisis de modulación espacial intrasitio, varias formas de análisis espacial regional, reconstrucción de sistemas de intercambio y determinación de estabilidad (temporadas del año). Por lo menos algunas conclusiones arqueológicas preliminares están disponibles en algunos de esos rubros. La información proviene casi exclusivamente de la porción del sur de California de la región yumana occidental (ver figura 5), quizás porque las investigaciones arqueológicas hasta ahora han sido más extensas en esa área.

\section{Clasificación de sitios}

Distintos modelos sobre la organización comunitaria de los yumano de occidente compiten teniendo diferentes implicaciones para la tipologia de sitios arqueológicos. La práctica arqueológica prevaleciente en la región ha sido la de distinguir tipos cualitativamente como villas, asentamientos temporales y sitios de procuración/proceso y extracción.

La tipologfa cualitativa se basa frecuentemente en criterios de presencia y ausencia, tales como la presencia de un "depósito arqueológico bien desarrollado" o como el número de diferentes tipos de restos presentes (herramientas de piedra lasqueada y desperdicio, herramientas líticas de superficie, cerámica, restos de fauna, objetos ceremoniales-religiosos. 


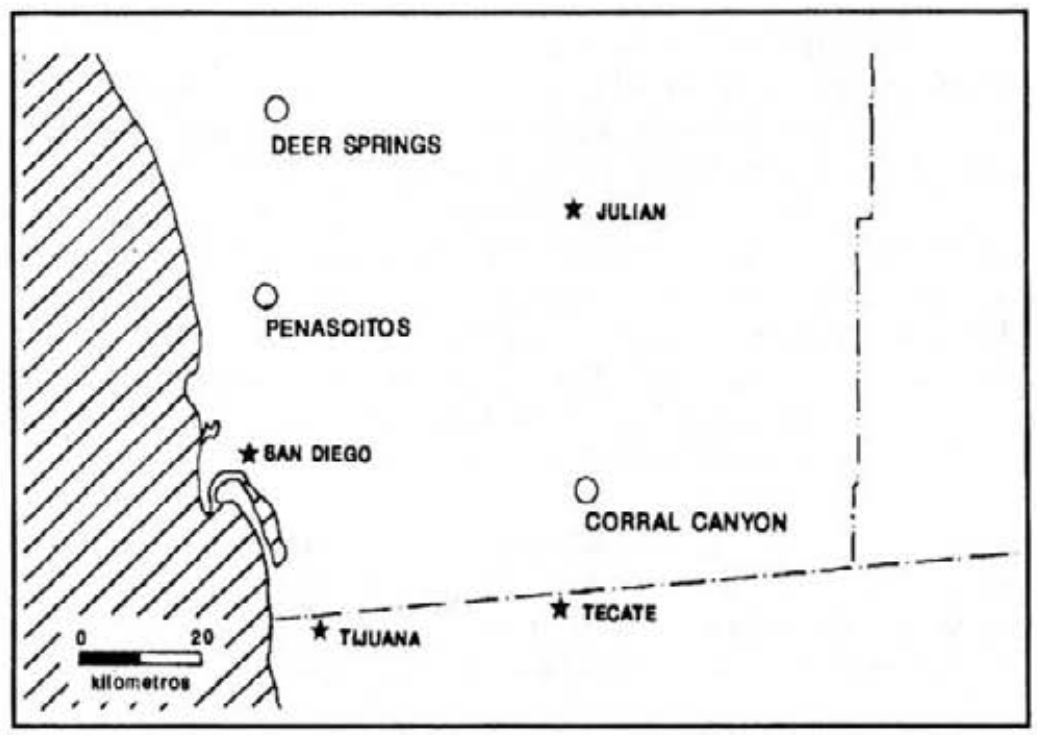

FIGURA 5. Áreas de investigación arqueológicas relacionadas en la organización comunitaria yumana del oeste.

etc.) Esta tipología tiene más probabilidades de éxito en el caso de un modelo altamente estructurado de organización comunal aborigen como el que menciona Shipek, que predice una villa central para cada banda territorial, con estancias periféricas (¿quizas los "campamentos temporales"?) Un modelo incluyendo recolectores organizados logísticamente, en vez de forrajeadores, está implícito por la tipología (Binford, 1983: 337-356).

El modelo alternativo de organización comunitaria yumana occidental sugiere que no existen rompimientos cualitativos dentro del espectro de sitios de habitación. Sin embargo, se espera que esos sitios formen una continuidad cuantitativa, de pequeño a grande. Tres dimensiones cuantitativas diferentes, conceptualmente distintas, pero usualmente difícil de distinguir, empíricamente, determinarían la riqueza y tamaño del sitio: 1) el tamaño del grupo social que ocupaba el sitio, 2) el período de su estancia, y 3) el número de veces que tales ocupaciones se repitieron. El modelo aquí favorecido sugiere que, entre los yumanos occidentales de la prehistoria tardía, las tres dimensiones variaban continua y no discontinuamente, yendo respectivamente de familias a agrupaciones de varios cientos de gentes, de ocupaciones de un día a varios meses, y de una ocupación ocasional a siglos de uso repetido. 
Aunque algunas observaciones no rigurosamente cuantificadas, ni extensivas aplicadas para el condado de San Diego y específicamente al área del cañon Corral de la porción interior de tierra alta del condado (ver figura 5); (Laylander y Christenson, 1988a:8991) dan apoyo al modelo cuantitativo. Incuestionablemente los sitios más grandes y más ricos contienen mayor diversidad de tipos de artefactos; sin embargo, antes de que interpretaciones funcionales sean inferidas de esa gran diversidad, es necesario mostrar que el contraste no solamente refleja diferencias en índices de preservación o descubrimiento, o "error de muestro" en los sitios más reducidos. Tomando en cuenta estas consideraciones se propone aquí que las "villas", o "campamentos temporales", la mayoría de los "sitios de procesamiento", y muchos sitios de restos líticos y cerámicos representan esencialmente el mismo tipo de sitio funcional: áreas de asentamiento ocupadas temporalmente por uno o más grupos tamaño-familia, en los que tanto se llevaban a cabo actividades de procuración y mantenimiento en la medida que se necesitaban.

\section{Modulación espacial intrasitio}

El análisis de la variabilidad horizontal dentro de sitios de la prehistoria tardía del área yumana occidental puede ayudar a distinguir el espectro de actividades representadas y la magnitud de la diferenciación de roles dentro del grupo social ocupante. Además, la separación de áreas de actividad y su repetición a través del área puede indicar tanto que la densidad del depósito refleja principalmente ocupación por un grupo social grande (quizá indicando arqueológicamente por la repetición de conjuntos de elementos asociados a una actividad) o también una ocupación de larga duración (con evidencia de conjuntos de rasgos muy pronunciados pero poco en número) o reocupación repetida (superposición e indefinición de conjunto de elementos asociados a una actividad fija). Un principio importante de análisis espacial intrasitio ha sido elaborado por Hector (1984 y 1988). El patrón general parece ser uno de mínima diferenciación consistente en áreas de actividad, sugiriendo ocupaciones temporales e inconstancia en el tamaño e identidad de los grupos ocupantes.

\section{Análisis espacial regional}

El análisis de la ubicación de sitios arqueológicos puede ser útil para el estudio de la organización comunitaria, sobre todo con relación a dos aspectos. Primero, las correlaciones ambientales de la ubicación de sitios pueden indicar el criterio de la selección de la localidad por los yumanos 
del occidente, a su vez, estos criterios pueden sugerir un espectro de funciones, en términos de explotación de recursos que se llevaron a cabo en los sitios. Segundo, la densidad geográfica con la que los sitios (de varios tamaños y tipos) ocurren puede ayudar a resolver el problema de si fueron utilizados asentamientos centralizados relativamente fijos o bien localidades cambiantes y si la aglomeración y fragmentación de grupos residentes fueron la norma.

El tema de densidad de sitio ha sido considerado en dos estudios recientes. En cañón Corral (Laylander y Christenson, 1988a), fueron encontrados diferentes asentamientos prehistóricos tardíos en un área aparentemente restringida para haber soportado tantas villas permanentes contemporáneas. Por otro lado, sitios más pequeños de usos múltiples y sitios de función especial estaban agrupados a corta distancia de los sitios más grandes, en vez de haber estado localizados más hacia los extremos donde podían haber funcionado con un rol logístico apoyando las áreas de villas-base. En el área de Peñasquitos (Laylander, 1989), el sistema hidrológico Soledad, que tiene una longitud de $29 \mathrm{~km}$ y un área de aproximadamente $250 \mathrm{~km}^{2}$, parecería un caso casi perfecto para el territorio de una banda autónoma diegueñá de la prehistoria tardía, de acuerdo a modelos de Shipek y Meigs. Sin embargo, por lo menos seis asentamientos importantes de la prehistoria tardía que tienen atributos arqueológicos generalmente asociados con "villas" han sido identificados dentro del escurrimiento, y sitios similares han sido también encontrados en sistemas de escurrimiento adyacentes. Fechamientos radio carbono e hidratamiento de obsidiana están disponibles para cuatro de las seis "villas" de Soledad, y ninguna de esta evidencia apoya alguna sucesión cronológica en la ocupación de asentamientos, por lo menos medidos en siglos y no en años o décadas.

\section{Sistemas de intercambio}

La distribución de materiales locales y exóticos dentro de los depósitos arqueológicos de la región yumana occidental también ofrece claves relativas al sistema de asentamientos y a los movimientos estacionales de sus habitantes. Un modelo de asentamientos de villas pequeñas, territorialmente compactos y permanentes, sugerirían una fuerte concentración de materiales de ocurrencia local dentro del territorio de una comunidad única. En una escala regional más amplia, tal modelo podría predecir una suave disminución en la frecuencia de materiales exóticos regionales con incrementos en las distancias a las fuentes del recurso, reflejando un movimiento de materiales línea abajo de una comunidad a otra. Estudios 
arqueológicos sobre la ocurrencia local de materiales, incluyendo roca volcánica y concha marina, al contrario, sugieren uso rutinario de recursos moderadamente distantes; estudios de la regionalmente exótica obsidiana, sugieren adquisiciones a través de intercambio durante las congregaciones estacionales de varios grupos diferentes de todas las regiones en áreas de tierras altas (Laylander y Christenson, 1988a:97-105; 1988b; Laylander 1989:180-190).

\section{Determinación de estacionalidad}

Sería difícil sobrestimar la importancia potencial de las determinaciones de estacionalidad para poner a prueba modelos de organización comunitaria yumana occidental. Sin embargo, pocas de esas determinaciones han sido hechas arqueológicamente en esta región (cf. Killingley, 1980 y 1981; Laylander, 1989:175-179). El estudio reciente más prometedor proviene del sitio de Deer Springs justo al norte de la región Yumana en territorio Luiseño, un sitio de habitación de la prehistoria tardía en donde la interpretación de un fuerte patrón de ocupación estacional fue apoyado utilizando patrones de incremento de crecimiento en otolitos de peces y en molares de venado (Quintero, 1987).

\section{CONCLUSIONES}

La literatura etnográfica publicada sobre la población occidental de hablantes de la lengua yumana en el norte de Baja California y sur de California contiene interpretaciones divergentes sobre la organización comunitaria con respecto a temas tales como la pertenencia a la comunidad, territorialidad y liderazgo. La evaluación de la evidencia parece favorecer el que chumules o grupos con una nomenclatura y una ubicación definida exógamos, de descendencia patrilineal, fueron las unidades aborígenes de más alta categoría, poseyendo territorio y teniendo líderes designados pero también que comunidades residentes eran de composición fluida, que los miembros del chumul pasaban porciones substanciales del afio dispersos fuera del territorio chumul, y que miembros de familias que no pertenecen al chumul frecuentemente compartían el uso del asentamiento chumul.

Arqueologicamente, se sugiere que este modelo de fluidez comunitaria está apoyado por varias líneas de evidencia: una continuidad en tamaño y complejidad entre sitios prehistórico-tardíos, indefinición de áreas de actividad diferentes dentro de sitios; la densidad con que los asentamientos mayores ocurren regionalmente; la proximidad de sitios pequeños de habitación y sitios de uso especial a los sitios principales; la modulación 
de la frecuencia con que materiales de ocurrencia local y regional-exóticos ocurren en sitios e indicaciones de mera ocupación estacional de asentamientos principales.

\section{BIBLIOGRAFÍA}

ALMSTEDT, Ruth F. 1982 The Kumeyaay and 'lipay. En: Clyde M. Woods (ed), APSSDG\&E Interconnection Project, Miguel to the Colorado River and Miguel to Mission Tap. Report submitted to San Diego Gas and Electric Company, San Diego.

BINFORD, Lewis R. 1983. Working at Archaeology. Academic Press: New York.

CARRICO, Richard L. 1983. "A Brief Glimpse of the Kumeyaay Past: An Interview with Tom Lucas. Kwaaymii of Laguna Ranch". Journal of San Diego History 29.

CLINE, Lora L. 1980. The Kwaaymii: Reflections on a Lost Culture. Imperial Valley College Museum Society Occasional Paper No.5.

- 1984. Just Before Sunset. J and L Enterprises: Jacumba, California. University of California Anthropological Records 1.

DRUCKER, Philip. 1987. Culture Element Distributions: Southern California.

- 1941. Culture Element Distributions: XVII, Yuman-Piman, University of California Anthropological Records 6.

GIFFORD, Edward W. 1918. Clans and Moieties in Southern California. University of California Publications in American Archaeology and Ethnology 14.

- 1926. Miwok Lineages and the Political Unit in Aboriginal California. American Anthropologist 28.

- 1931. The Kamia of Imperial Valley. Bureau of American Etnology Bulletin. No.97.

GIFFORD, E.W. y R.H. Lowie. 1928. "Notes on the Akwa'ala Indians of Lower California". University of California Publications in American Archaeology and Ethnology 23.

GRAHAM, William R. 1981. "A Cultural Resource Survey of the Laguna Mountain Recreation Area". Report submitted to Cleveland National Forest, Escondido, California.

HECTOR, Susan Melinda. 1984. "Late Prehistoric Hunter-Gatherer Activities in Southern San Diego County, California", Tesis doctoral, Department of Anthropology, University of California. Los Ángeles. 
- 1988. The Identification of Activity Areas within Late Prehistoric Sites: A Case Study of the Rimbach Site. San Diego, California. Proceedings of the Society for California Archaeology 1.

HEIZER, Robert F. (Editor). 1978. California. Handbook of North American Indians. Vol. 8, William G. Sturtevant, editor general Smithsonian Institution: Washington, D.C.

HEIZER,Robert F., y Alfred L. Kroeber. 1976. "For Sale: California at 47

Cents per Acre". Journal of California Anthropology 3(2).

HICKS, Frederic Noble. 1963. "Ecological Aspects of Aboriginal Culture in the Western Yuman Area." Tesis doctoral, Department of Anthropology, University of California, Los Ángeles.

- 1974. "The Influence of Agriculture on Aboriginal Socio-political Organization in the Lower Colorado River Valley." Journal of California Anthropology. No. 1.

HINTON, Thomas B., y Roger C. Owen. 1957. "Some Surviving Yuman Groups in Northern Baja California." América Indigena 17(1).

KELLY, William H. 1977. "Cocopa Ethnography." Anthropological Papers of the University of Arizona. No. 29. Tucson.

KILLINGLEY, John S. 1980. "Seasonality of Mollusk Collecting at Hubbs's Midden Site 1959:VI:28A". Pacific Coast Archaeological Society Quarterly 16(4).

- $\quad$ 1981. "Seasonality of Mollusk Collecting Determined from O-18 Profiles of Midden Shells." American Antiquity 46.

KROEBER, A.L. 1925. "Handbook of the Indians of California". Bureau of American Etnology Bulletin. No. 78.

LAYLANDER, Don 1985. "Some Linguistic Approaches to Southern California's Prehistory". San Diego State University Cultural Resource Management Casual Paper 2(1).

- 1987. "Sources and Strategies for the Prehistory of Baja California." Tesis de maestría. Department of Antropology, San Diego State University.

- 1989. "Phase II Archaeological Investigations at Site CA-SDi5383, Peñasquitos Área, San Diego, California." Report Submitted to California Department of Transportation, San Diego.

LAYLANDER, Don, y Lynne E. Christenson. 1988a. "Results of a Data Recovery Program for Corral Canyon Prehistoric Archaeological District, San Diego County, California". Report submitted to Cleveland National Forest, Escondido, California.

- 1988b. "Corral Canyon and Late Prehistoric Exchange in Inland San Diego County, California". Proceedings of the Society for California Archaeology 1. 
LUOMALA, Katherine. 1976. "Flexibility in Sib Affiliation among the Diegueño". En: Native Americans: A Theoretical Retrospective, editado por Lowell John Bean y Thomas C. Blackburn. Ballena Press: Ramona, California.

- 1978. "Tipai and Ipai en California", editado por Robert F. Heizer. Handbook of North American Indians, vol. 8, William G. Sturtevant, editor general Smithsonian Institution: Washington, D.C.

MACDOUGAL, D.T. 1907. "The Desert Basins of the Colorado Delta." Bulletin of the American Geographical Society 39 (12).

MAY, Ronald V. 1975. "A Brief Survey of Kumeyaay Ethnography: Correlations between Environmental Land-Use Patterns, Material Culture, and Social Organization". Pacific Coast Archaeological Society Quarterly 11(4).

MEIGS, Peveril, III. 1939. "The Kiliwa Indians of Lower California". Ibero-Americana. No.15.

- 1971. "Creation Myth and Other Reflections of the Neji Mishkwish". Pacific Coast Archaeological Society Quarterly 7(1).

- 1972. "Notes on the La Huerta Jat'am, Baja California: Place Names, Hunting, and Shamans". Pacific Coast Archaeological Society Quarterly 8 (1).

- 1977. "Notes on the Paipai of San Isidoro, Baja California". Pacific Coast Archaeological Society Quarterly 13 (1).

MICHELSEN, Ralph. 1977. "The Territoriality of the Native Americans in the Northern Highlands of Baja California". Baja California XV Simposio.

MIXCO, Mauricio J. 1983. Kiliwa Texts: "When I Have Donned My Crest of Stars". University of Utah Anthropological Papers. No. 107.

OCHOA ZAZUETA, Jesús Ángel. 1977. "El Mito Fundamental en la Vida Social Kiliwa: Análisis Contextual". Calafia. No. 3.

- $\quad$ 1978. Los Kiliwa: Y el Mundo se Hizo Así, Serie de Antropología Social, Colección INI. No.57.

- 1979. "Distribución Actual de los Grupos Indígenas de Baja California". Calafia 4.

- 1982. Sociolingüística de Baja California. Universidad de Occidente: Los Mochis, Sinaloa.

OWEN, Roger C. 1962. "The Indians of Santa Catarina, Baja California, Mexico: Concepts of Disease and Curing". Tesis de doctorado. Department of Anthropology, University of California, Los Ángeles.

- 1965. "The Patrilocal Band: A Lingüistically and Culturally Hybrid Social Unit." American Anthropologist. No. 67. 
- 1966. "The Social Evolution of Northern Baja California Indian Bands". Baja California Iv Simposio.

QUINTERO, Leslie. 1987. "Room and Board at Deer Springs: Faunal Analysis as an Aid to Settlement Sutudies". Tesis de Maestría. Department of Anthropology, San Diego State University.

SHIPEK, Florence C. 1982. "Kumeyaay Socio-Political Structure". Journal of California and Great Basin Anthropology. No. 4.

- 1984. "Memorial to Mrs. Rosalie Pinto Robertson". Journal of California and Great Basin Anthropology. No. 6.

- 1988. Pushed into the Rocks: Southern California Indian Land Tenure, 1769-1986. University of Nebraska Press: Lincoln.

SPIER, Leslie. 1923. "Southern Diegueño Customs". University of California Publications on American Archaeology and Ethnology. No. 20.

STEWART, Omer C. 1978. Litigation and its Effects. En California, editado por Robert F. Heizer. Handbook of North American Indians. Vol. 8, William G. Sturtevant, editor general. Smithsonian Institution: Washington, D.C.

TOFFELMIER, G., y K. Luomala. 1936. "Dreams and Dream Interpretation of the Diegueño Indians of Southern California". Psychoanalytic Quarterly. No. 5. 